\title{
Gulf Medical Audit - An Analysis of Medical Casualties Evacuated to the UK from the Gulf during Operation Granby.
}

\section{Capt T J Hodgetts}

MRCP(UK), DipIMC RCSEd, RAMC

Specialist

\section{Col G E Ratcliffe}

MSc, MRCP, L/RAMC

Senior Consultant

Department of Medicine, Queen Elizabeth Military Hospital, Woolwich, London SE18 4QH

SUMMARY: The 61 personnel, 60 male, evacuated from the Gulf to Queen Elizabeth Military Hospital on $\vec{\circ}$ medical grounds between late October 1990 and mid March 1991 are reviewed with particular regard to previous: medical history, previous medication, and appropriate PULHHEEMS grading. The percentage evacuated was $\omega$ 0.24\% of Army personnel involved in "Operation Granby" which is considered acceptably small.

\section{Introduction}

"Operation Granby" involved 1(Br) Armoured Division as part of the multi-national force contributing to the defence of Saudi Arabia following the Iraqi invasion of Kuwait on 2 August 1990. All army personnel requiring extended medical investigation, treatment or convalescence that could not be provided by the field General Hospitals (33 and 205) were evacuated to the Queen Elizabeth Military Hospital. A total of 61 medical casualties was received between 26 October and 17 March. Of these 55 were regular, 4 reservists and 2 territorial.

\section{Method}

Fifty-nine sets of notes were analysed after the patient had been discharged from hospital using a standardised questionnaire (one set of notes was untraceable and one set in BAOR). Key points scrutinised were - Territorial Army/Regular/Reservist; length of time in theatre before illness; area of operations; medical grade (PULHHEEMS category) on deployment; medication on deployment; if illness was an exacerbation of an existing condition; date admitted and evacuated from field hospital; Casevac (casualty evacuation) diagnosis; Aeromed (aero-medical) complications; date admitted and discharged from this hospital; final discharge diagnosis; medical grade and disposal.

\section{Results}

Table 1 gives a breakdown of casualty figures by sub-speciality and Table 2 by Arm or Corps.

\section{Neurology}

Thirteen neurological cases were received, the commonest problem being a convulsion (Table 3 ).

Three and probably four of the six subjects suffering a generalised convulsion not due to alcohol withdrawal occurred in those who had previously experienced a fit. The three subjects who had definite documented previous isolated convulsions (occurring in 1986-88) had all
Table 1

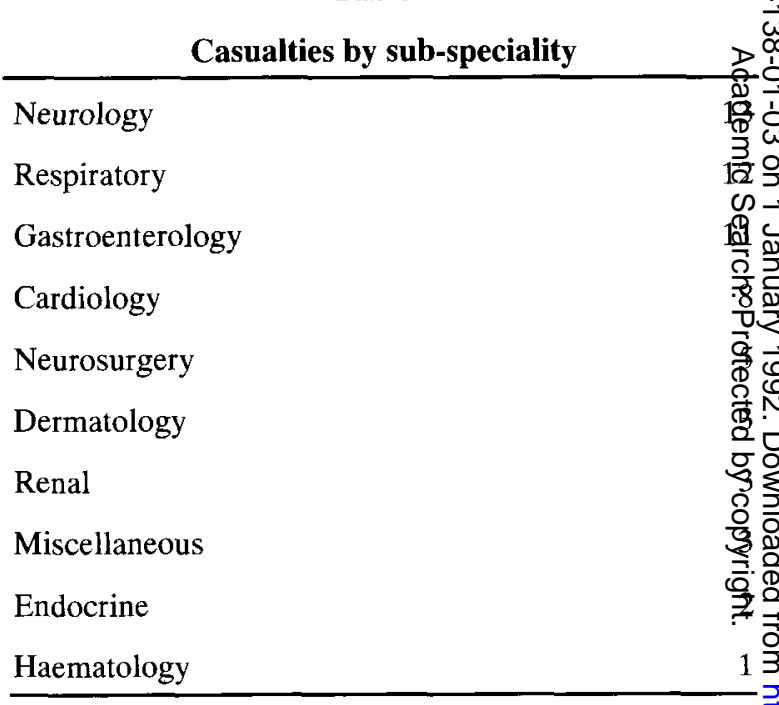

had at that time a normal standard electroencephalogram (EEG), and one also had a normal fasting, sleep deprived (FSD) record. Two had had normal computerised tomography (CT) scans and all three had been downgraded $\mathrm{P} 7 \mathrm{HO}$ for at least six months, when, after no recurrence, they were regraded $\mathrm{P} 2 \mathrm{FE}$. Of those with $\cong$ definite recorded previous fits all recurred after sleep? deprivation of up to 48 hours, two of whom had fasted for 18-24 hours. One of the cases suffering a first fit had also fasted and been sleep deprived. Sudden cessation of a regular alcohol intake was thought to be a possible contributory factor in two of the six.

At QEMH EEGs were performed in all bar one, $\frac{D}{0}$ whose history and abnormal liver function tests clearly suggested alcohol withdrawal as the cause. Fasting, $\widetilde{N}$ sleep deprived recordings were performed when the ${ }_{N}$ standard EEG was normal: two standard EEGs were $\mathrm{N}$ abnormal, one recurrent case, and one suggestive of $\omega$ 
Table 2

Casualties by arm or corps

RAMC

12

INF (incl. Foot Guards)

RCT

RAOC

RA

RE

REME

R SIGS

RAC

RPC

ACC

temporal lobe symptoms. All FSD EEGs were normal. Computerised tomography scans were performed in all, either at QEMH or in the Gulf, and were normal. In all cases an assessment of P7 HO Ex NI was given.

Other neurological cases were:

(i) Bell's palsy

(ii) Cluster headaches recurring over six years, invariably responding to ergotamine which was not available in the Gulf. He attended a field hospital five times in 21 days for analgesia and anti-emetics.

(iii) Post-traumatic epilepsy and migraine in whom EEG and CT were normal. Graded P7 HO Ex NI for twelve months.

(iv) Recurrent syncope following smoke inhalation. All investigations were normal and graded P2 FE.

\section{Respiratory}

Asthma: Four patients were evacuated with asthma (Table 4). All had had previous symptoms and were on regular therapy in a category of $\mathrm{P} 2 \mathrm{FE}$. Three were medically discharged, the fourth graded P3 LE.

The first case relapsed wearing a respirator on two occasions, and Nerve Agent Pre-Treatment Set (NAPS) (pyridostigmine $30 \mathrm{mg} 8$ hourly) reintroduction seemed to worsen his condition. The second had recurrent wheeze soon after arrival in the Gulf, precipitated by a sandstorm. The third case, a TA soldier, had been diagnosed as asthmatic in Belize six months previously but was never investigated, nor adequately treated before proceeding to the Gulf. The fourth case relapsed after a chest infection: his symptoms coincided with the reintroduction of NAPS.
Pneumothorax: Two cases, one recurrent who was referred for thoracic surgery; the other was caused by a cough fracture of a rib.

Pneumonia: Three cases of lobar pneumonia were evacuated an organism was isolated in only one.

Bronchitis: Two cases, one of which was possible exacerbated by ubiquitous cement dust in the unit loca tion, the other complicated by severe bilateral otitis? externa.

\section{Gastroenterology}

Hepatitis A: 9 cases were evacuated. Accepting ars incubation period of 14-42 days (1), one was incubating the disease on mobilisation, and three were infected in the Gulf. Identifiable sources were apparent in four, and were suggested in the remainder.

At QEMH diagnosis was confirmed in three (positive HAVIgM): all were negative for surface antige

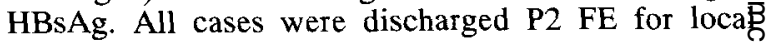
review.

Hepatitis B: One case occurred five weeks afte $\vec{\omega}_{0}$ arrival in the Gulf. No source was identifiable. His serology was positive for anti-HBc and $\mathrm{HBe}$. Clinically he improved rapidly but he was graded $\$$ LE for local review in BAOR. Appropriate advice screening of his family was given.

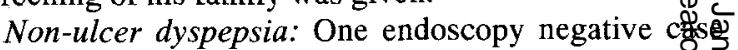
was evacuated. He had previously had a duodenal uleeg but had run out of his histamine 2 receptor antagon

Cardiology

Angina: A 35 year old bandsman with a twe month history of recurrent exertional chest pain tog evacuated following a positive sub-optimal maxima exercise test in the Gulf. He had not been previousl investigated. Exercise test and thallium scan were sifgo gestive of antero-lateral ischaemia. Provisional cardis catheter report was normal. He was graded P7 HO the interim.

Re-entrant tachycardia: An officer diagnosed it 1978 as suffering from Lown-Ganong-Levine syn drome was evacuated after a recurrence of paroxysma tachycardia with haemodynamic impairment precipi

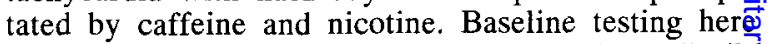
was normal, but an AV nodal re-entrant tachycardia (1) no accessory pathway) was induced electrophysiolog cally; on the basis that he avoids known precipitants $h$ remains $\mathrm{P} 2 \mathrm{FE}$.

Pericarditis: An officer who suffered pericarditis i January 1990, relapsed in July 1990, had further recurô rence three months later in the Gulf, was evacuated Cardiological investigation was normal. He was grade P7 HO for follow up.

Atrial fibrillation: A 35 year old reservist was evacu․ㅡ. ated with atrial fibrillation related to a dilated carro diomyopathy, probably secondary to alcohol. He admitted excessive alcohol consumption, even in the Gulf. He was detoxified and graded P8. 


\section{$T J$ Hodgetts and $G E$ Ratcliffe}

Atypical chest pain: Four cases were evacuated: one initially diagnosed as hypertrophic obstructive cardiomyopathy in whom no cardiovascular abnormality was found, a viral myocarditis which resolved, and two cases of costochondritis, one of which was recurrent, the other with associated bronchial hyper-reactivity associated possibly with. NAPS.

\section{Dermatology}

Three cases of chronic relapsing dermatological conditions were evacuated.

Darier's disease (Keratosis follicularis): This case had been stable for many years but relapsed in the Gulf. He was treated with etretinate, steroid creams and responded. He was graded P5 FT.

Eczema: An NCO with a six month history of palmar eczema which rapidly worsened and became more disseminated in the Gulf. In-patient therapy in the Gulf was complicated by chickenpox and he was evacuated. He responded at QEMH and returned to BAOR where follow up and medical grading decisions were taken.

Psoriasis: An NCO with a three year history of psoriasis relapsed in the Gulf and was evacuated. Therapy continues and a decision on appropriate grading has yet to be made.

\section{Endocrine/Metabolic}

Diabetes Mellitus: A Senior NCO with known insulin dependent diabetes was sent to the Gulf in a category of P3 LE. Control in the desert was moderate and he was evacuated, after which control was rapidly regained.

Idiopathic Hypercalciuria with Nephrolithiasis: A Senior NCO was evacuated with a further episode of renal colic. The latter originally occurred in 1983 when investigations revealed idiopathic hypercalciuria: he passed one or more calculi spontaneously, was

Table 3

Analysis of convulsions occurring on Operation Granby

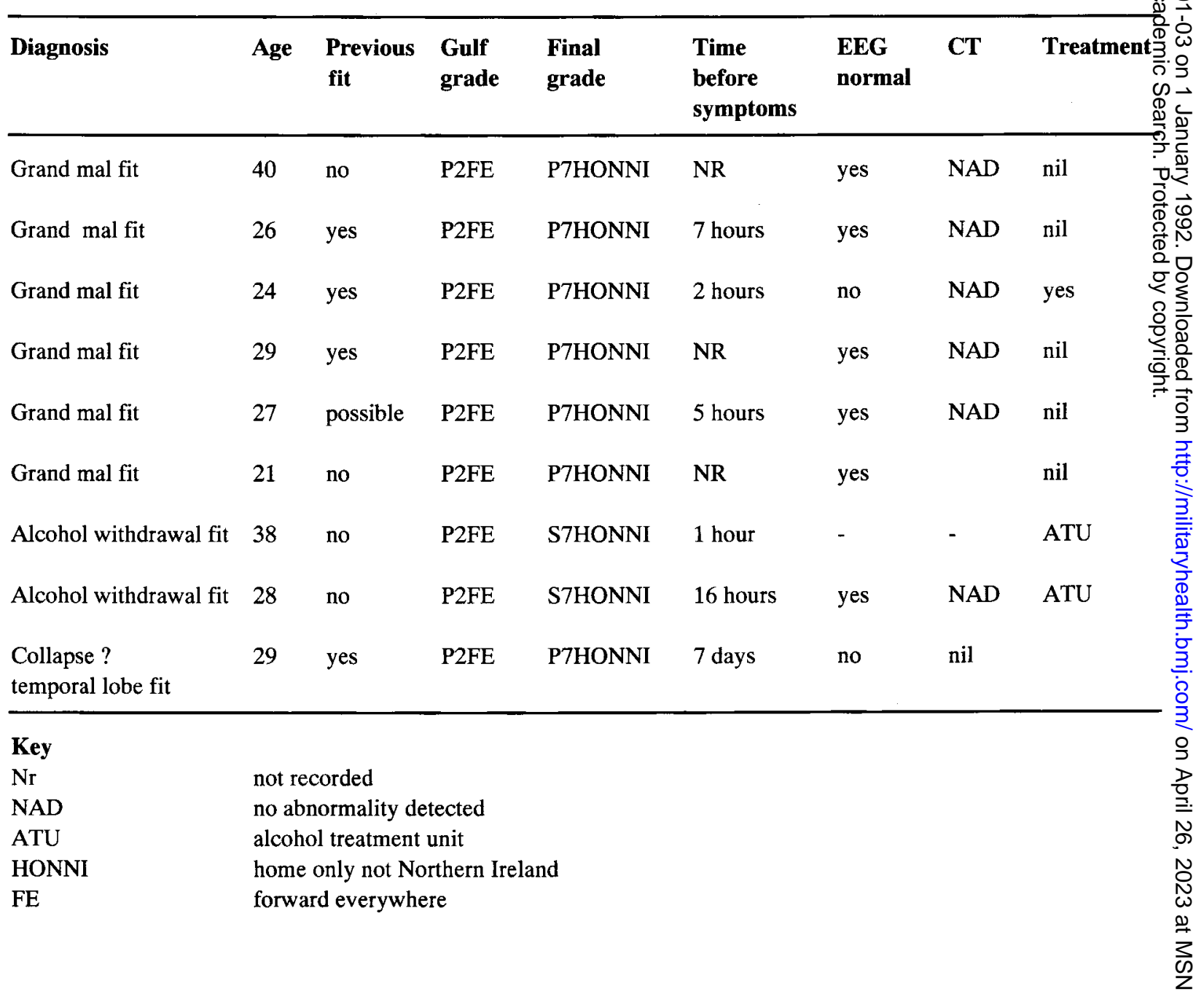


instructed about suitable diet and graded P5 FT. He had no symptoms for at least four years and was regraded P2 FE in 1989. Intravenous Urography (IVU) in the Gulf revealed multiple bilateral renal calculi with bilateral ureteric obstruction and, following evacuation, bilateral ureteric stents were inserted prior to lithotripsy. A decision on appropriate grading has yet to be made.

\section{Haematology}

Acute Myeloid Leukaemia: A Senior NCO presented with an upper respiratory infection, malaise and purpura. The haematological diagnosis was made within a few hours, and he was evacuated immediately. He deteriorated rapidly and, despite massive blood transfusions, he died in QEMH six hours after arrival, and only 48 hours after initial diagnosis.

\section{Nephrology}

Haematuria: Three cases were evacuated: urethritis diagnosed at the time of cystoscopy in one, prostatitis in another, and in the third haematuria was not confirmed at any time at QEMH. No changes in grading were made.

\section{Neurosurgery}

Head injury patients at QEMH are cared for by the Honorary Consultant in Neurosurgery to the Army assisted by the physicians. It is therefore, appropriate to include five head injuries. An extradural haematoma was surgically evacuated in the Gulf after CT confirmation. Three cases resulted from road traffic accidents, one of which occurred in combat. Two of these suffered significant cerebral oedema. Two other soldiers who developed retrograde amnesia after being concussed were evacuated.

\section{Miscellaneous}

Pregnancy: A servicewoman with seven weeks amenorrhoea who presented in the Gulf 10 days after arrival. She was concerned about the possible effects on this planned pregnancy, of the various vaccinations and NAPS, and needed to be strongly reassured of the low risks involved.

Chickenpox/Pilonidal Sinus: The abscess was incised in the Gulf, but was slow to heal.

\section{Discussion}

Neurology

Joint Service Publication (JSP) 346 states (2): "proven epilepsy, with a few exceptions, is to be assessed P8. It is unwise, however, to base the diagnosis on the history of one fit". On these grounds it is usual, following a first fit, to downgrade the soldier P7 $\mathrm{HO}$ Ex NI, and to forbid driving and weapon handling for one year, but to upgrade to P2 FE at this time if no recurrence occurs. Recent estimation of recurrence after an idiopathic, untreated isolated seizure is $40 \%$ at
Table 4

Analysis of asthmatics from Operation Granby

\begin{tabular}{llll}
\hline Case & $\begin{array}{l}\text { Time since } \\
\text { diagnosis }\end{array}$ & $\begin{array}{l}\text { Treatment } \\
\text { pre-Gulf }\end{array}$ & $\begin{array}{l}\text { Time in Gulf } \\
\text { before admission }\end{array}$ \\
\hline 1 & 2 months & Ventolin PRN & NR (short period) \\
2 & 8 months & Ventolin QDS & 4 months \\
3 & 6 months & Ventolin QDS & $\begin{array}{l}5 \text { days } \\
\text { Becotide QDS }\end{array}$ \\
4 & 10 years & Ventolin & $\begin{array}{l}5 \text { days } \\
\text { pre-exercise }\end{array}$ \\
\hline
\end{tabular}

All drugs were inhaled

$\mathrm{NR}=$ not recorded

two years (3): if the original EEG is abnormal this rises $\vec{\omega}$ to $83 \%$, and to $63 \%$ if FSD recording only is abnorm Increased risk factors are a first fit during sleep or g $_{3}$ wakening and evidence of tongue biting. A CT sc\$i after the initial fit demonstrated structural abnormafi:윽 ties in $5.5 \%$.

In our small series with a $40 \%$ recurrence rate afteeूa single fit it is tempting to suggest that a single fit is unacceptable risk for a combat soldier, particularly when the uncertainty of a battlefield may produce cōiditions of fasting and sleep deprivation.

\section{Respiratory}

JSP 346 states: "Serving personnel with asthma may be retained in an appropriate medical category, fit consultant advice, if the condition is mild, infrequetrit? or well controlled on treatment". This still allows cơ siderable scope for interpreting the suitable grade with $\vec{F}$ subjective variation between physicians. All four sol- 3 diers were serving with forward units and required the $\mathcal{F}$ grade P2 FE (4). Few would dispute that case 3 shouldo have been downgraded as unfit for Gulf service. It was perhaps difficult to anticipate the possible effects of stress, a respirator, climate and anticholinesterase med-פ ication in those with mild existent asthma. Physicians may have to be more aggressive when considering if these soldiers can remain combat effective (ie P2 FE) and whether, in a potentially reduced service, they have $\frac{}{3}$ any future at all.

\section{Gastroenterology}

No advice is given in JSP 346 on appropriate grad-음 ings for hepatitis - we believe advice on grading for $>$ those with positive hepatitis B serology would be valu-ㅡㅡ. able.

\section{Cardiology}

The main concern involved recurrence or exacerba- 
tion of existing conditions and whether appropriate gradings had been allocated to prevent some or all of these cases from going to the Gulf initially; we consider that the officer with two episodes of pericaditis in the six months prior to mobilisation should not have remained $\mathrm{P} 2 \mathrm{FE}$.

\section{Dermatology}

"The following skin diseases are likely to result in a lowering of $P$. . . endogenous eczema (very severe will be $P 8$ ) ... psoriasis (unless very mild and stable): when severe is to be graded P8." (JSP 346). Darier's disease is not mentioned specifically, but this may be worsened by exposure to the sun implying temperate zone service only (5). This implies that a recruit should be assessed as below retention standards and potential recruits should be refused. Whilst it is accepted that most psoriatics improve with sunshine, it may also trigger deterioration. In this individual, and in the case of eczema, it would seem appropriate to impose a category of P5 FT, if not medical discharge.

\section{Endocrine/Metabolic}

The picture of a soldier in full individual protection equipment drawing up insulin from a glass bottle and injecting himself on the battlefield is not one we would wish to encourage. The following points of the case should be considered:

(a) was his medical grade correct? - JSP 346 states: "Servicemen requiring insulin can, in certain circumstances, be retained in an appropriately reduced category, but, as a general rule, the need for insulin will demand an assessment of $P 8$ "

This clearly allows considerable variance for interpretation depending, perhaps, on the individual's ability to continue their trade unimpaired; to pass a BFT; the accurate control of their blood glucose; the presence or absence of diabetic complications; the perceived worth of the individual within a unit. With this in mind it is not possible to criticise the grade of $\mathrm{P} 3 \mathrm{LE}$.

(b) Should he have been sent to the Gulf? - The PULHHEEMS Administration Pamphlet (PAP) 1987 dictates the PULHHEEMS employment standards in war and states that for infantry (including Foot Guards and Para), "All ranks in infantry field force units should be P2 FE . . . (other than) individual exceptions . . . as agreed between posting authorities and commanding officers".

It is not known if this soldier had the explicit dispensation implied, but if this was so his posting to the war zone cannot be criticised either.
This soldier highlights the problem that service physicians quite frequently face in deciding an appro- $z$ priate grade for a skilled and valuable member of $a \stackrel{\Phi}{\circledR}$ peace-time army who has no obvious functional dis-? ability from his diabetes.

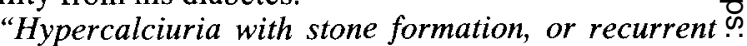
renal calculi should preclude tropical service, unless $\overrightarrow{\vec{F}}$ the hypercalciuria has been corrected by appropriate long term therapy. The following merit a P5 grading. . idiopathic hypercalciuria" (2).

Despite absence of symptoms in the case in question, 24 hour urinary calcium excretion, although improved, $\propto$ still remained $25 \%$ above the upper limit of normal at $\infty$ the time he was graded P2 FE. The criteria for his $\vec{\circ}$ upgrading were therefore questionable and urological advice had never been sought until his recent complica- $\vec{\omega}$ tions.

\section{Medication}

The possible role of NAPS in inducing hyper-reactiv- $\frac{\vec{\omega}}{\omega}$ ity or teratogenicity has been noted in the appropriats sections. In two of the asthma cases withdrawal of NAPS produced an apparent improvement in peak expo ratory flow rate within 48 hours.

\section{Conclusion}

The total number of evacuated medical casualties represents a tiny fraction $(0.24 \%)$ of the army personnel involved in "Operation Granby" and deployed in th Gulf over the five months of this survey. Audit is $\overrightarrow{0}$ nature highly critical. It has become clear, howevo 유, that several of the casualties should never have been sent to the Gulf: of these, some were inappropriate deployed not through any individual failure, but moge through the weaknesses of a flexible PULHHEENS system. It is only from analysis of our problems in weे that we can sensibly alter our parameters for service peace.

\section{REFERENCES}

1. Shanson D C Microbiology in Clinical Practice. Bristol 1982, Wright: 293

2. JSP 346 PUlhHEEMS: A Joint Service System of Medical Classification. Ministry of Defence, 1976.

3. Van Donselaar C, Geerts A, Schimsheimer R-J. Idiopathic first seizure in adult life: who should be treated? Br Med J 1991; 302:620-3.

4. PulHheEMS Administrative Pamphlet 1987. Ministry of Defence, 1987.

5. RYAN T J. Diseases of the skin. In Oxford Textbook of Medicine (2nd ed). Oxford 1987, Oxford University Press: 20.15. 